\title{
ALBINA The White Goddess - Mapping and Communicating Avalanche Risk in the European Alps
}

\author{
Karel Kriz \\ University of Vienna, Department of Geography and Regional Research, Austria karel.kriz@univie.ac.at
}

Keywords: Mountain Cartography, Risk Management, Avalanches, Geo-Communication

\begin{abstract}
:
With the increasing importance of communication in the context of risk management and disaster prevention in mountainous environments, the demand for adequate communication channels and cartographic representations is constantly rising. In particular, the presentation of a broad spectrum of geospatial topics such as avalanche awareness requires innovative cartographic methods and approaches that go beyond standard cartographic depiction procedures.
\end{abstract}

ALBINA is such a project that addresses this proposition. It embraces risk management with cartographic communication methods and stands for "The White Goddess" an allusion to snow avalanches. This cooperation project has the goal to publish a joint, multilingual avalanche bulletin in the entire European region of Tyrol, South Tyrol and Trentino. The aim is to inform the public daily about the avalanche situation as well as to communicate avalanche related information in an efficient and profound way. An online portal is currently being developed as part of an Interreg V-A Italy-Austria project in collaboration between the University of Vienna, the EVTZ Europaregion, the Austrian Avalanche Warning Service of Tyrol as well as the Italian Avalanche Warning Services of South Tyrol and Trentino. The developed communication structures promote and facilitate the exchange of spatial-temporal information between experts of neighboring regions as well as the public in a multi-lingual environment. The framework is supported by a software system that handles and visualizes meteorological data, observations, snow profiles and avalanche events of the entire region with a strong focus on cartographic communication. It furthermore offers the possibility to enter and manipulate the avalanche bulletin in a standardized way in order to optimize the exchange of information between the avalanche experts on duty.

In order to foster the efforts in avalanche awareness and communication three conceptual cornerstones have been identified according to international avalanche warning standards: (1) avalanche danger assessment and forecasting production, (2) timing and validity of publication and (3) effective geocommunication. Based on this alignment the international ALBINA project was launched to showcase the ability and strength of such an approach. This presentation will primarily focus on effective geocommunication clarifying the general framework as well as the communication structures and workflow within the overall system. Thereby explaining the methods and interaction between the available real-time data, the technical infrastructure, the human resources as well as the geo-communicational aspects of the system. Thereafter the individual cornerstones of the system will be discussed. These consist of various services dealing with the input and administration of avalanche relevant information, geodata processing and provision, map production and dissemination, meteorological map and diagram manipulation and creation as well as the design and conception of the frontend web-interface. Finally, the current state of the system will be presented exemplifying the geo-communicational procedures and methods.

This project is being funded by the Interreg Italia-Österreich programme (2017-E-001-INTERREG-IT-AT3004-ALBINA-CUP-B29G16000720006). 